Check for updates

Cite this: RSC Adv., 2019, 9, 41927

Received 29th August 2019

Accepted 1st November 2019

DOI: $10.1039 / c 9 r a 06870 h$

rsc.li/rsc-advances

\section{Mechanisms of pattern and colour generation of Chinese Tianmu glaze}

\author{
Xiaotao Shi, Yougen Yu, Qian Sun, Weiya Zhu, Cheng Peng and Jianqing Wu (D)* \\ Tianmu glaze wares are a very famous form of ancient Chinese porcelain. The samples were prepared with \\ local raw materials and traditional technology. X-ray diffraction, scanning electron microscopy, optical \\ microscopy and energy dispersive spectroscopy were used to analyse the phase composition, \\ microstructure and chemical composition of the Tianmu glaze. The results show that the patterns were \\ created by the process that includes phase separation, the iron-rich phase moving to the surface, the \\ growth of nanosized magnetite and hematite crystals, the aggregation of a thin crystal layer, and the \\ appearance and collapse of bubbles. Scattering, diffraction and interference of nanosized grains are the \\ primary colour rendering mechanism.
}

\section{Introduction}

Tianmu glaze wares, which are called Jian ware or Jianzhan, are produced in Jianyang, Fujian Province, China; these wares were popular during the Song Dynasty (approximately A.D. 960-1279). Tianmu glaze wares have a variety of colourful patterns on their surfaces such as 'hare's fur' and 'oil spot', because of their unique formulas and firing processes. Many experts have studied phase-separated crystalline glazes such as Tianmu glaze..$^{1-9}$ In this paper, the microstructures of oil spot Tianmu glaze were studied, and the formation mechanism of oil spot speckles was probed into. Zhou et al. ${ }^{1}$ investigated a commercial Tianmu glaze bowl and a sample that they prepared. They determined that there was a crystal layer with a thickness of one to a few hundred nanometres on the Tianmu glaze surface that was composed of pseudo-cubic spinel dendrite crystals. The light interference, which resulted from the crystal layer governed the colour appearance of the glaze. Catherine Dejoie et al. ${ }^{2}$ found that the surface patterns of an ancient oil spot Tianmu wares were exclusively made of $\varepsilon-\mathrm{Fe}_{2} \mathrm{O}_{3}$ crystals up to several micrometers in size and were organized in a periodic two-dimensional fashion. They believed that the surface colour and patterns are linked to the crystallization of iron oxides. Shi et al. ${ }^{10-13}$ explained the effect of $\mathrm{Ca}^{2+}$ and $\mathrm{P}^{5+}$ ions on the phase separation in Jun ware glaze containing iron oxide. They speculated that glaze colour is a structural colour that is caused by amorphous photon crystals and a chemical colour from $\mathrm{Cu}$ ions. In this study, we prepared samples from local raw materials using traditional technology in Jianyang, where Tianmu glaze originated. The crystal phase and microstructure of the products were

School of Material Science and Engineering, South China University of Technology, Guangzhou 510640, China. E-mail: ceramicgroup@163.com analysed by X-ray diffraction, optical microscopy, energy dispersive spectroscopy and field emission electron microscopy. On the basis of the abovementioned results, the pattern and colour formation mechanisms of Tianmu glaze were proposed.

\section{Experimental procedure}

\subsection{Raw materials}

The raw materials for the glaze include Jianyang glaze stone, feldspar, quartz, calcite, calcined bovine ashes, talc and other mineral raw materials. The chemical composition is shown in Table 1. The chemical raw material $\mathrm{Fe}_{2} \mathrm{O}_{3}$ is a colouring agent, and its purity is $\geq 98 \%$.

The green body was composed of Jianyang local ironcontaining and local high-alumina clays. The chemical compositions of glaze and green body are shown in Table 2 .

\subsection{Glaze slurry preparation}

The glaze raw materials were batched and loaded into a planetary mill jar. The weight ratio of raw materials : ball : water

Table 1 Chemical composition of raw materials

$\begin{array}{llllllllll}\mathrm{SiO}_{2} & \mathrm{Al}_{2} \mathrm{O}_{3} & \mathrm{P}_{2} \mathrm{O}_{5} & \mathrm{Fe}_{2} \mathrm{O}_{3} & \mathrm{CaO} & \mathrm{MgO} & \mathrm{K}_{2} \mathrm{O} & \mathrm{Na}_{2} \mathrm{O} & \mathrm{I} . \mathrm{L}\end{array}$

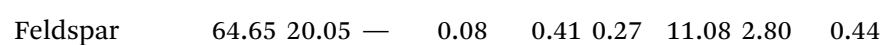

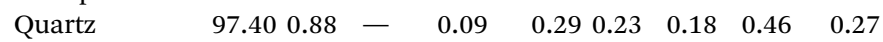

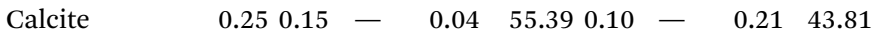

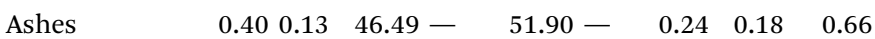

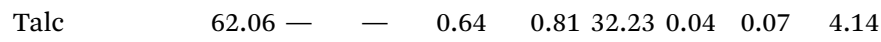

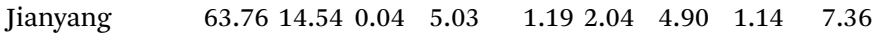
glazed stone Iron oxide 
Table 2 Glaze and body chemical composition

\begin{tabular}{lccccccccc}
\hline & $\mathrm{SiO}_{2}$ & $\mathrm{Al}_{2} \mathrm{O}_{3}$ & $\mathrm{P}_{2} \mathrm{O}_{5}$ & $\mathrm{Fe}_{2} \mathrm{O}_{3}$ & $\mathrm{CaO}$ & $\mathrm{MgO}$ & $\mathrm{K}_{2} \mathrm{O}$ & $\mathrm{Na}_{2} \mathrm{O}$ & I.L \\
\hline Glaze & 47.69 & 11.18 & 0.74 & 7.17 & 8.25 & 3.64 & 4.02 & 0.89 & 16.42 \\
Body & 61.48 & 20.07 & 0.15 & 5.25 & 0.10 & 0.29 & 2.44 & - & 10.22
\end{tabular}

was $1: 2: 0.8$ and the milling time was $30 \mathrm{~min}$. The fineness of the glaze was controlled by the sieve residue to less than $0.3 \%$ after a 150 mesh screening. The glaze consistency was adjusted by adding water, and the water content of the glaze was controlled to be approximately $50 \%$.

\subsection{Firing process}

The glaze slurry was coated on the green bodies by the immersion method. After drying, the wares were fired in an electric furnace with a round hole for adding small pine fragments. The firing temperature was raised from room temperature to $1370{ }^{\circ} \mathrm{C}$ in 7 hours under oxidizing atmosphere and maintained for one and a half hours at the highest firing temperature. Then, pine wood fragments were added through the round hole, and the wares were soaked in a heavy reducing atmosphere for another 1 hour after the hole was sealed. During the natural cooling process, the temperature was decreased from $1370{ }^{\circ} \mathrm{C}$ to $1150{ }^{\circ} \mathrm{C}$, and a weak reducing atmosphere was maintained by adding a small amount of pine wood into the
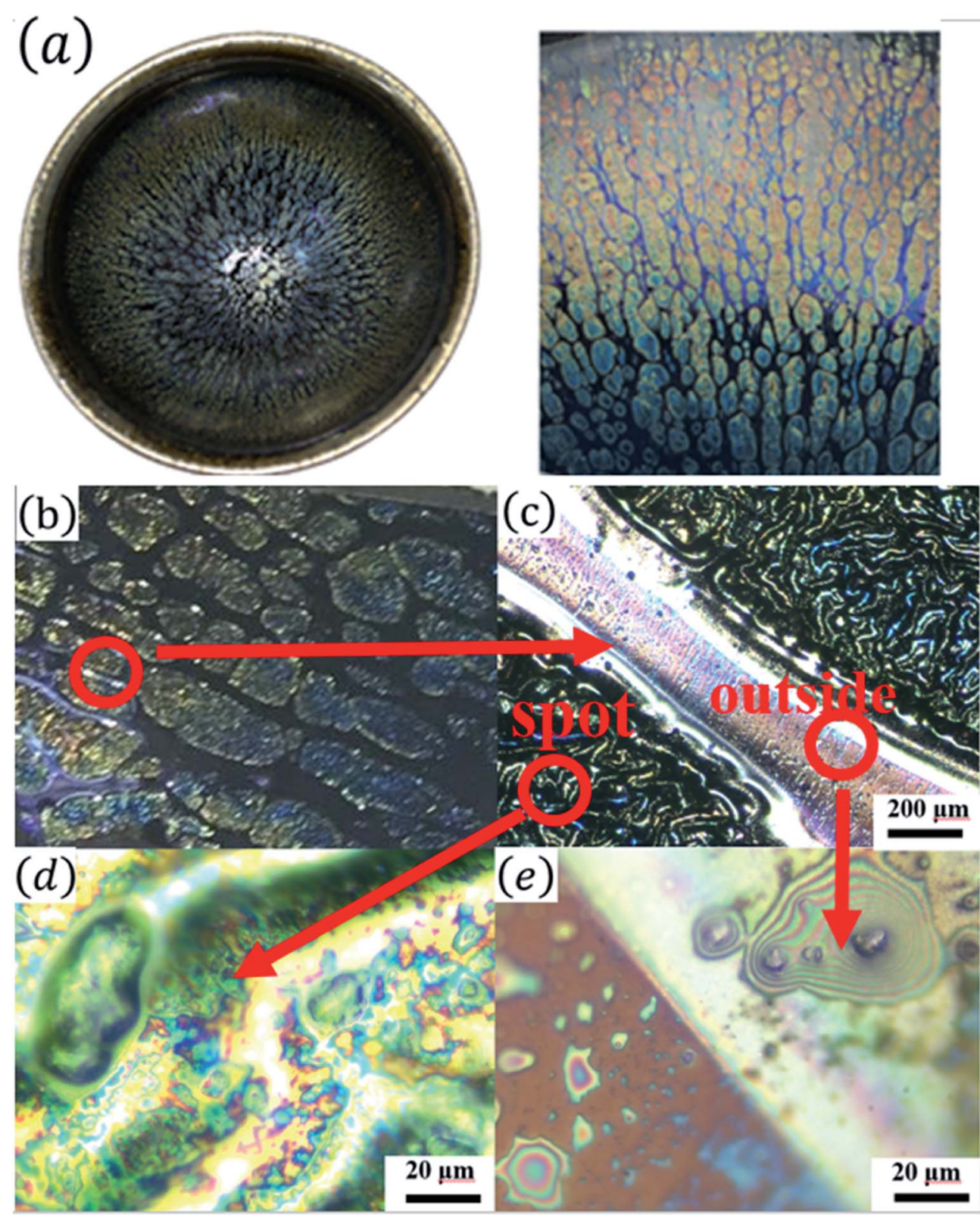

Fig. 1 Optic microscopy images of the Tianmu glaze surface. (a) Tianmu glaze ware; (b) oil spot patterns; (c) oil spot patterns of the red circled area in (b); (d) in the oil spot; (e) outside the oil spots. 


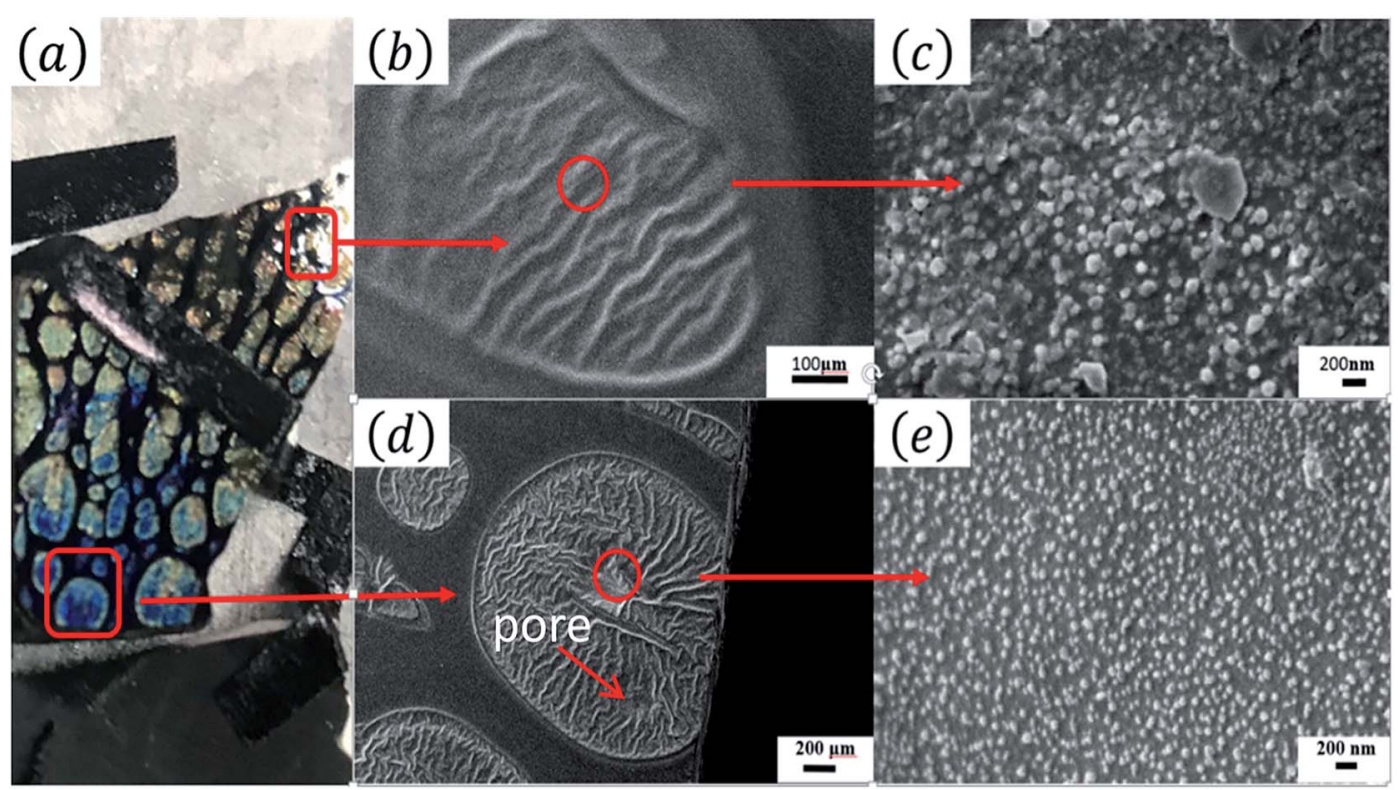

Fig. 2 Optical and scanning electron microscopy images of the glaze. (a) Optic photograph; (b) SEM image of the yellow spot; (c) SEM image of the grains on the yellow spot; (d) SEM image of the blue spot; (e) SEM image of the grains on the blue spot.

furnace. Below $1150{ }^{\circ} \mathrm{C}$, the atmosphere was changed to oxidizing.

\subsection{Measurements}

The crystal phases were determined by X-ray diffraction analysis (PANalytical X'pert PRO, Almelo, Netherlands) using $\mathrm{Cu} \mathrm{K \alpha}$ radiation $(40 \mathrm{kV}$ and $40 \mathrm{~mA})$ in the range of $10^{\circ}$ to $70^{\circ}$. The XRD pattern was recorded with a step of $0.0178^{\circ}$, and the duration of each step was 8 seconds. Secondary electron and backscattered electron images were observed by scanning electron microscopy (ZEISS Merlin and EVO 18, Oberkochen, German). An energy dispersive X-ray spectrometer (INCA Energy 300, Oxford instruments, High Wycombe, UK) attached to the SEM was used to obtain the chemical composition of different microscopic regions. The glaze was etched with a $1 \mathrm{vol} \% \mathrm{HF}$ solution for 30 seconds before observation. ${ }^{14,15}$

\section{Results and discussion}

Fig. 1(a) shows the optical images of the Tianmu glaze ware. There are many colourful oil spots on the surface. Fig. 1(b)-(e) show the optical microscopy images acquired at different magnification times. Fig. 1(d) and (e) show the typical rainbowlike appearance inside and outside the oil spot area. The colour varies around salient points and forms clear interference fringes. This reminds us that the beautiful colour of Tianmu glaze is mainly obtained by thin film interference.,16,17

Fig. 2 shows the optical and scanning electron microscopy images of the glaze. The glaze patterns are composed of oil spots with wrinkled surfaces, as shown in Fig. 2(b) and (d). On the surfaces of oil spots, clear hole markings are observed which were left behind when gas escaped from the bubbles (Fig. 2(d)). Further close-up observation of the red circled areas in Fig. 2(b) and (d) show that the surfaces are covered by nanosized particles (Fig. 2(c) and (e)). The particles on the blue spot (Fig. 2(e)) are significantly finer than those on the yellow spot (Fig. 2(c)). According to the principle of physical optics, when the particle size of phase separation crystallization is less than $100 \mathrm{~nm}$, the colouring mechanism of ceramic glazes conforms to Rayleigh scattering. The scattering intensity is determined using the following formula. ${ }^{16,18}$

$$
I(\lambda)_{\text {scattering }} \propto \frac{I(\lambda)_{\text {incident }}}{\lambda^{4}}
$$

where $I(\lambda)_{\text {incident }}$ is the distribution function of the incident light intensity, and $\lambda$ is the wavelength of the light. The smaller the $\lambda$, the easier is the Rayleigh scattering. Because blue light is at the short wavelength end of the visible spectrum; the structural colour developed by the Rayleigh scattering appeared blue. In Fig. 2(d), Rayleigh scattering dominates the structure colour, and the oil spots appeared blue. The structural colour of the glaze is caused by optical effects (e.g., interference, diffraction, and reflection), when the size range of the particles is comparable to the optical wavelength range..$^{16,18}$

The XRD pattern (Fig. 3(b)) indicates that in the oil spot area the crystalline phases are mainly magnetite and hematite. This is consistent with the minerals of other ancient Jianye Tianmu glazes. ${ }^{19-21}$ Fig. 3(c)-(f) are the elemental mapping results. Clearly, $\mathrm{Fe}$ and $\mathrm{Ca}$ are concentrated in the oil spot areas, and $\mathrm{Si}$ and $\mathrm{Al}$ have higher contents outside the spot area. In general, modifiers (e.g., $\mathrm{K}_{2} \mathrm{O}, \mathrm{Na}_{2} \mathrm{O}, \mathrm{CaO}$, and $\mathrm{MgO}$ ) increase the $\mathrm{O}$ : Si ratio in the melt and destroy the bridging linkage of the silica network. The free energy of the glass system with high potential ions is high, and it is difficult to form a thermodynamically stable and uniform glass; thus phase separation spontaneously occurs. The potential of $\mathrm{Ca}^{2+}$ is 1.89 , and it easily forms strong bonds with $\mathrm{O}^{2-}$, Therefore, 

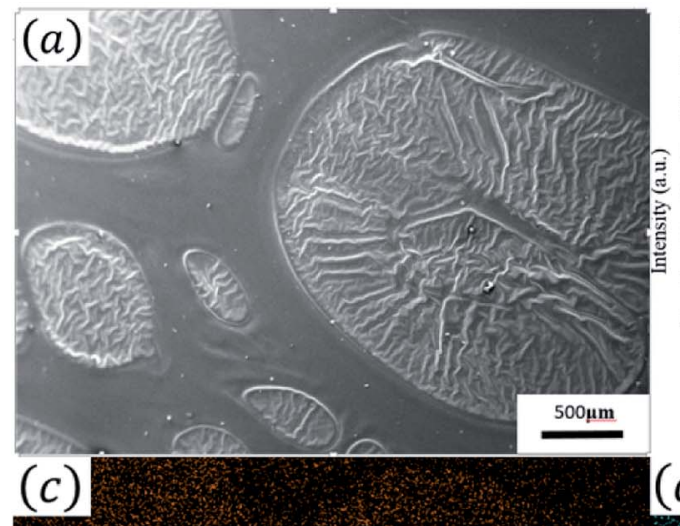

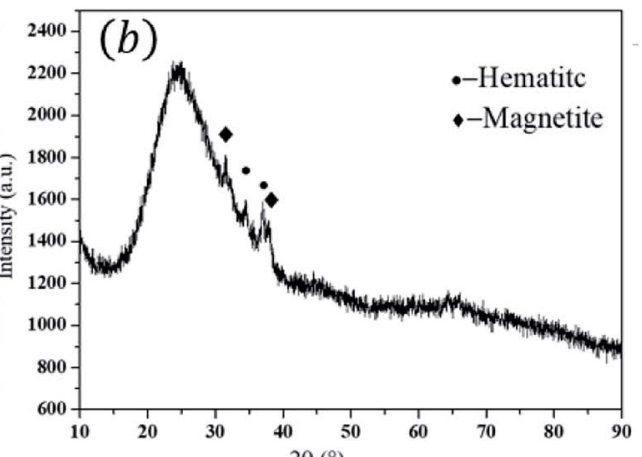

$(d)$

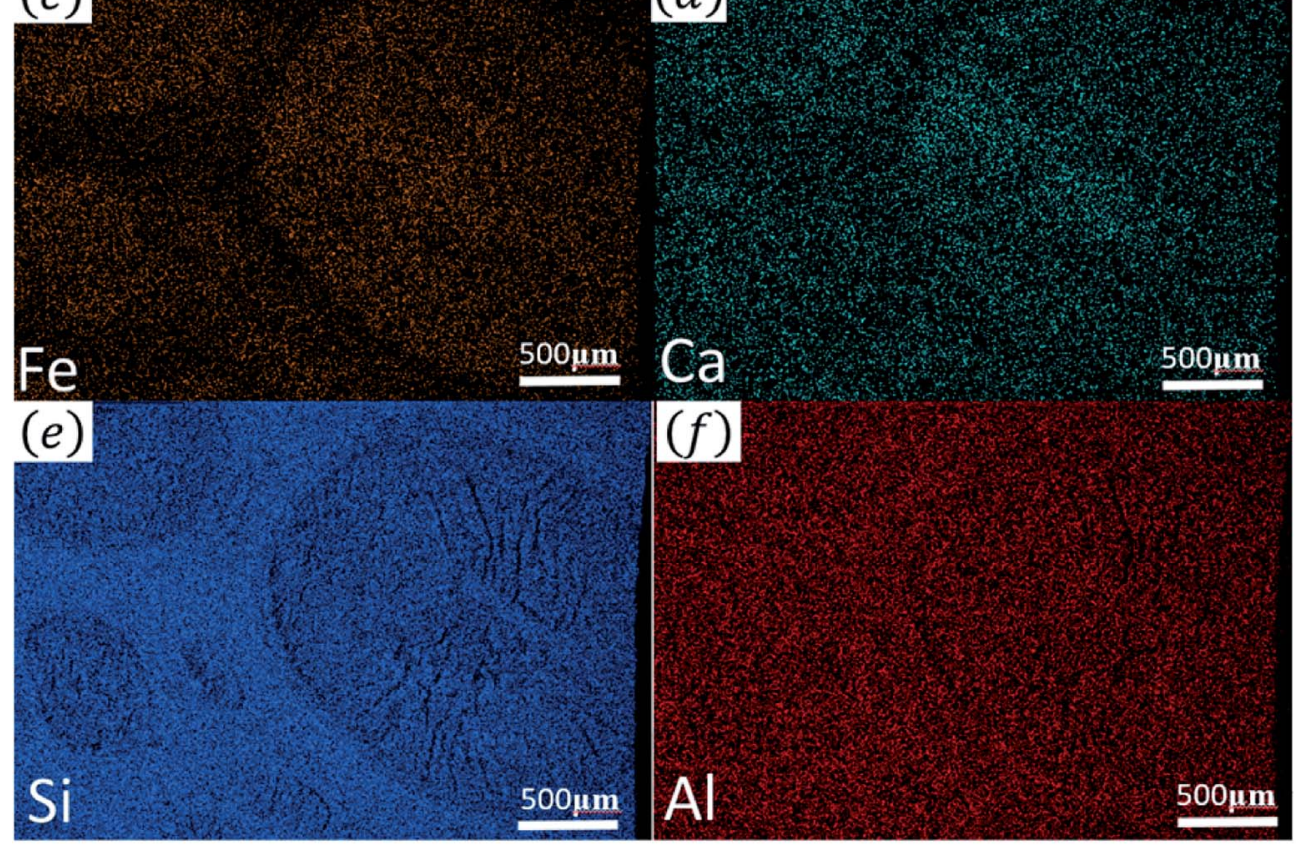

Fig. 3 XRD pattern and the elemental mapping analysis. (a) SEM image of the area used for element mapping; (b) XRD pattern; (c-f) element distribution maps.

Tianmu glaze with a high Ca content is prone to phase separation at high temperatures.

The presence of spots with wrinkled and stomata surfaces is a good confirmation of the relationship between the iron-rich phase and the spots. In high-temperature melting glaze, $\mathrm{Fe}_{2} \mathrm{O}_{3}$ is reduced to $\mathrm{FeO}$ and release oxygen. Clearly, the iron-rich phase releases more oxygen and forms many bubbles in the phase that makes the phase 'lighter' than the iron-poor phase. The oxygen bubbles in the iron-rich phase brought the phase clusters to the glaze surface by the buoyancy force. During the process of bubbles reaching the surface, small bubbles in the iron-rich phase merged into large bubbles and emerged on the glaze surface. Then, the bubbles burst due to the oxygen pressure. Once the pressure exceeded the strength of the bubble wall, the bubble broke at the weakest point, and the gas escaped from the created hole. As the bubbles collapsed oil spots with wrinkled surface were formed. Bubble surface is a gas-liquid interface, which is an ideal place for crystal nucleation. As the bubble formed, iron oxide grains began to nucleate and grow on the bubble walls.
Fig. 4 shows the cross-sectional SEM micrographs of the Tianmu glaze. Fig. 4(b)-(d) are the successively enlarged SEM images of the red circled area in Fig. 4(a). Fig. 4(d) clearly shows that the grains reached the glaze surface and formed a thin film with a thickness of approximately $100 \mathrm{~nm}$ to $200 \mathrm{~nm}$. The crystal grains in the spot region are mainly hematite (refractive index of 2.94-3.22) and magnetite (refractive index of 2.42), and the refractive indices of both crystals are higher than that of the glaze glass phase (1.5 to 1.8). Because the grain intensity in the thin film is much higher than that in the other areas, the film can be consider to have a relatively high equivalent refractive index. When visible light shines on the surface, the corresponding film interference colour is presented. Meanwhile, coherent diffraction and scattering occur in the grain region, and a reverse colour occurs on the upper and lower sides of the film. Thus, the glaze colour is a combination of film interference colour, coherent diffraction colour and small grain or particle scattering colour.

Fig. 4(c) shows that below the surface grain layer, there is an inner wall grain layer. Because the layer is a combination of two 

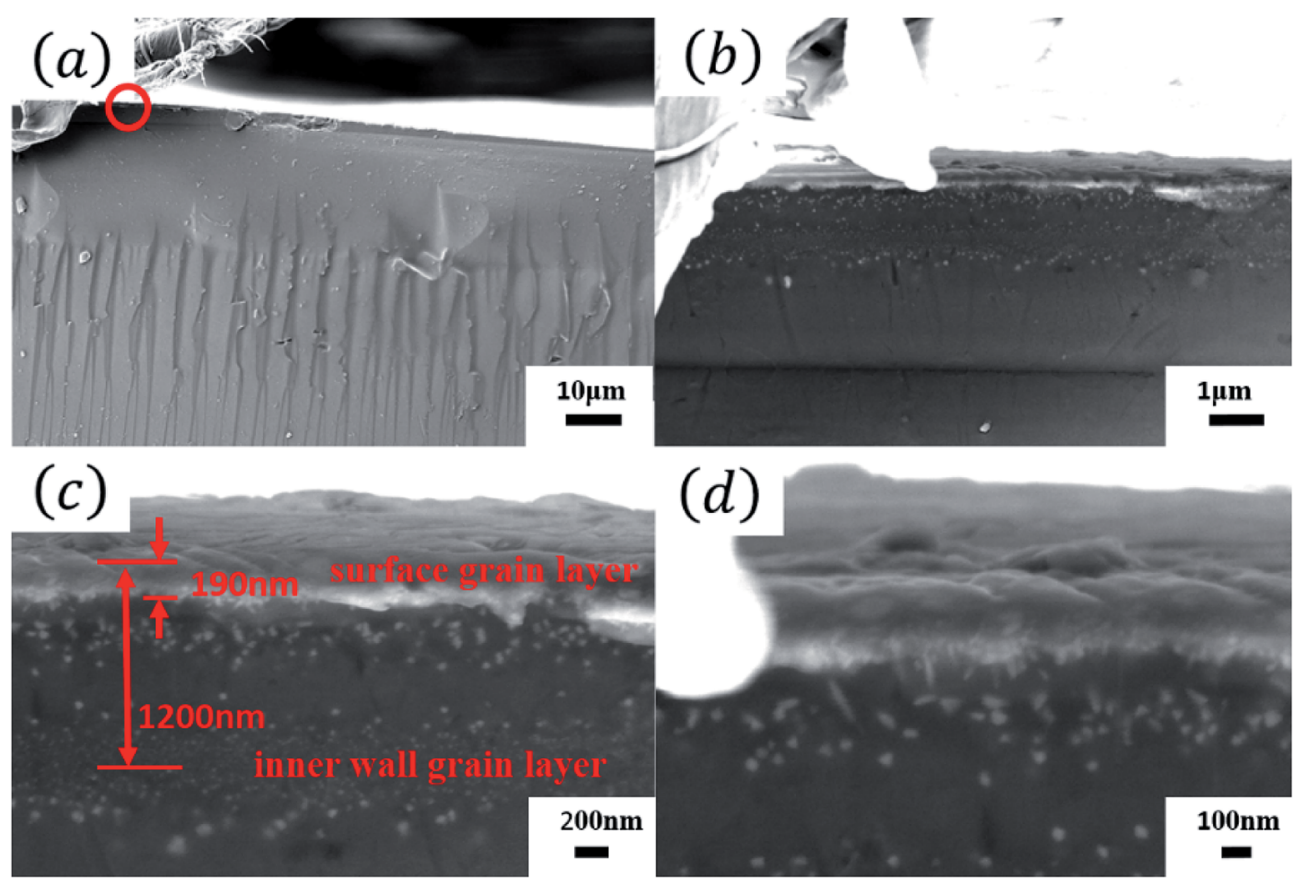

(d)

Fig. 4 (a) Cross-sectional SEM images of the Tianmu glaze. (b-d) Successively enlarged SEM images of the red circled area in (a).

inner walls of a collapsed bubble, the thickness of the bubble wall, which emerged from the glaze surface, is approximately $1290 \mathrm{~nm}$, as shown in Fig. 4(c). Fig. 5 shows the EDS analysis results of the glaze cross section. From the inside to outside, the Fe content increases. This confirms that the iron-rich phase moved towards the glaze surface due to the buoyancy force, and the iron content in the outer layer was higher than that in the inner layer.

Fig. 6 is a schematic diagram of the crystal layer formation on the surface of the Tianmu glaze. The above mentioned figure

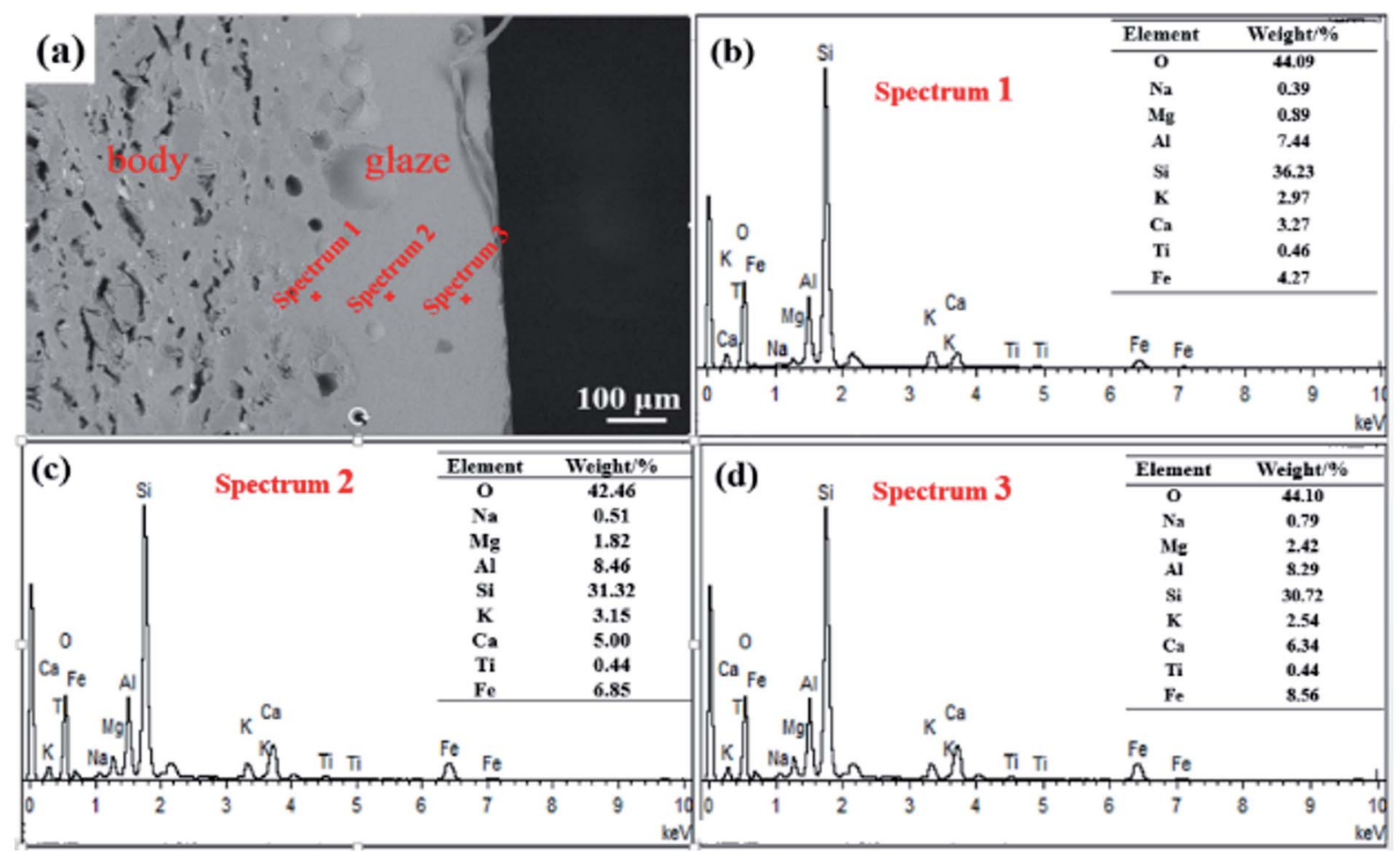

Fig. 5 EDS analysis of the glaze cross section. 


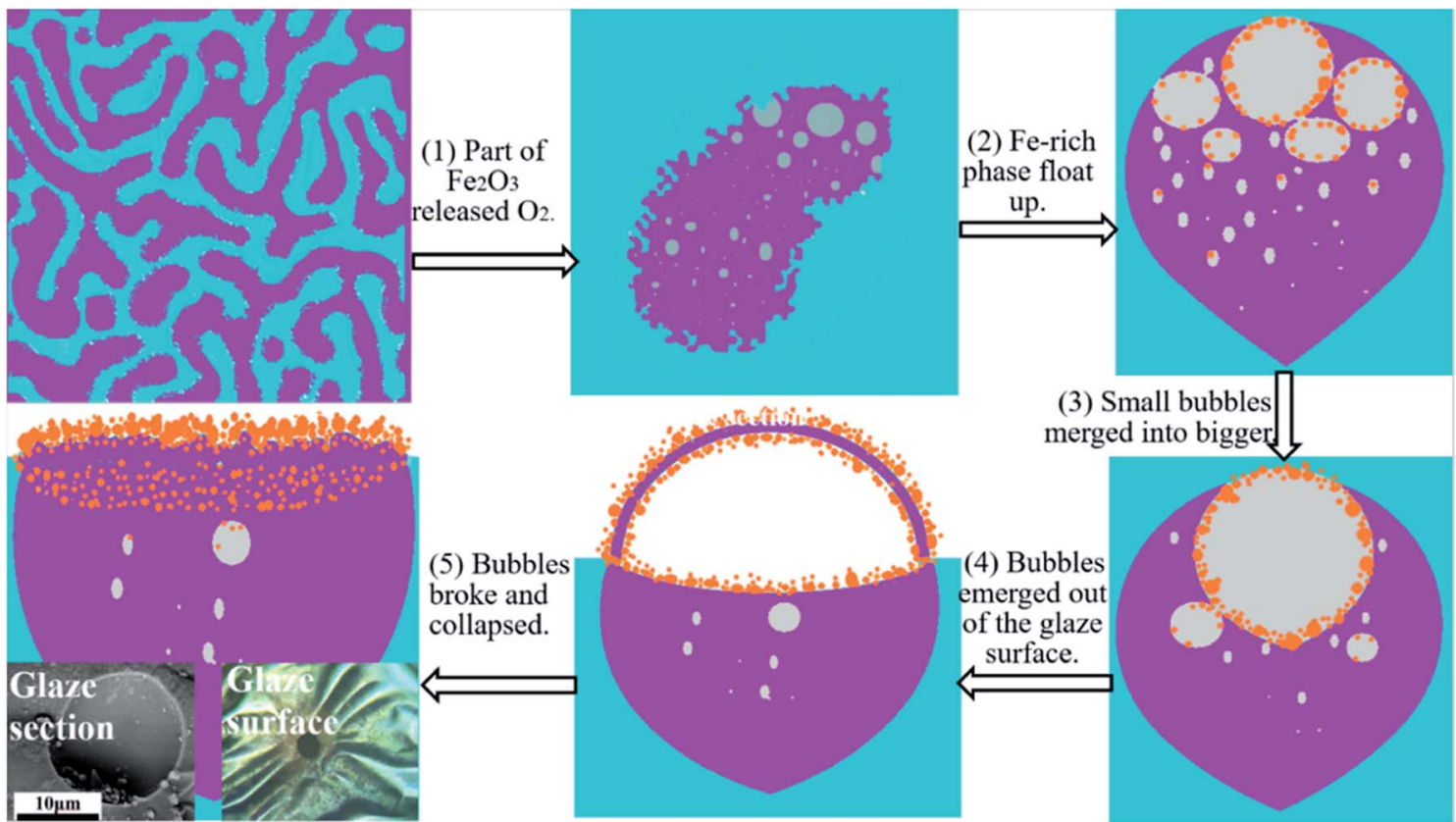

Fig. 6 Schematic diagram of the crystal layer formation.

shows the evolution of spots and colours of oil spot Tianmu glaze. (1) At high temperature, phase separation occurs, part of $\mathrm{Fe}_{2} \mathrm{O}_{3}$ is reduced to $\mathrm{FeO}$, and oxygen is released. (2) The Fe-rich phase release more oxygen and makes the phase 'lighter' than the Fe-poor phase; the buoyant force causes the bubbles in the Fe-rich phase to float up. Crystalline nuclei formed on the inner wall of the bubbles. (3) Small and medium bubbles merged into large bubbles, and the grains grew on the inner walls. (4) Bubbles emerged out of the glaze surface, and grains formed on both sides of the bubble wall. (5) Bubbles broke and collapsed, and oil spot speckles with wrinkled and dense nanosized grains surfaces were formed.

\section{Conclusion}

The process and mechanism of the Tianmu glaze pattern and colour formation are described as follows. At high temperature the melting glaze was separated into iron-rich and iron-poor phases. The iron rich phase released more oxygen and formed bubbles, which made it 'lighter' than the iron-poor phase; thus, the iron rich phase moved to the glaze surface. The iron content in the glaze gradually increased from inside to outside. Hematite and magnetite grains preferentially grew on the bubble wall and finally formed an approximately $100 \mathrm{~nm}$ to $200 \mathrm{~nm}$ thick film. The thickness of the bubble wall on the glaze surface is approximately $1200 \mathrm{~nm}$. In addition to being coloured by iron oxide, the Tianmu glaze colour is a combination of film interference colour, coherent diffraction colour and small grain or particle scattering colour.

\section{Conflicts of interest}

There are no conflicts to declare.

\section{Acknowledgements}

This work was financially supported by the National Natural Science Foundation of China (Grant No. 51472092) and the Major Science and Technology Project of Foshan City, Guangdong, China (Grant No. 2016AG101315).

\section{References}

1 C. Chiang, H. F. Greer, R. Liu and W. Zhou, Ceram. Int., 2016, 42, 7506-7513.

2 C. Dejoie, P. Sciau, W. Li, L. Noé, A. Mehta, K. Chen, H. Luo, M. Kunz, N. Tamura and Z. Liu, Sci. Rep., 2014, 4, 4941.

3 J. Hou, T. Pradell, Y. Li and J. Miao, J. Eur. Ceram. Soc., 2018, 38, 4290-4302.

4 J. Zhu, P. Shi, F. Wang and T. Zhao, J. Eur. Ceram. Soc., 2015, 35, 4603-4609.

5 W. Li, J. Li, Z. Deng, J. Wu and J. Guo, Ceram. Int., 2005, 31, 487-494.

6 R. F. Huang, X. Q. Chen and S. P. Chen, Chin. Ceram., 1988, 17-21.

7 O. C. Pereira and A. M. Bernardin, J. Hazard. Mater., 2012, 233-234, 103-111.

8 K. Pekkan, H. Başkırkan and M. Çakı, Ceram. Int., 2018, 44, 4789-4794.

9 J. Wu, M. Zhang, T. Hou, Q. Li and J. Wu, Ceram. Int., 2015, 41, 6851-6857.

10 P. Shi, F. Wang, J. Zhu, B. Zhang, T. Zhao, Y. Wang and J. Wang, Ceram. Int., 2018, 44, 16407-16413.

11 P. Shi, F. Wang, J. Zhu, H. Yang, Y. Wang, Y. Fang, B. Zhang and J. Wang, J. Eur. Ceram. Soc., 2018, 38, 2228-2233.

12 B. Zhang, J. Zhu, P. Shi, F. Wang, J. Wang and Z. Ren, J. Eur. Ceram. Soc., 2019, 39, 1925-1931. 
13 J. Zhu, P. Shi, F. Wang, T. Zhao and H. Jiang, Ceram. Int., 2016, 42, 5250-5257.

14 S. Wang, C. Peng, Z. Huang, J. Zhou, M. Lü and J. Wu, J. Eur. Ceram. Soc., 2014, 34, 541-547.

15 S. Wang, C. Peng, M. Lü and J. Wu, J. Am. Ceram. Soc., 2013, 96, 2054-2057.

16 J. D. Forster, H. Noh, S. F. Liew, V. Saranathan, C. F. Schreck, L. Yang, J. Park, R. O. Prum, S. G. J. Mochrie, C. S. O'Hern, H. Cao and E. R. Dufresne, Adv. Mater., 2010, 22, 2939-2944.
$17 \mathrm{H}$. W. Yin, Study on the coloring mechanism and preparation method of structural color, Fudan University, 2008.

18 J. Hou, T. Pradell, Y. Li and J. Miao, J. Eur. Ceram. Soc., 2018, 38, 4290-4302.

19 W. Li, H. Luo, J. Li, J. Li and J. Guo, Ceram. Int., 2008, 34, 1473-1480.

20 X. Li, J. Lu, X. Yu, J. Zhou and L. Li, Ceram. Int., 2016, 42, 15269-15273.

21 Y. Xu, Y. Qin and F. Ding, Ceram. Int., 2017, 43, 8636-8642. 